Journal of Mathematics and Statistics 5 (4): 401-407, 2009

ISSN 1549-3644

(C) 2009 Science Publications

\title{
Cost Analysis of K-Out of-n Repairable System with Dependent Failure and Stand by Support Using Kolmogorov's Forward Equations Method
}

\author{
M.Y. Haggag \\ Department of Mathematics, Faculty of Science, Al-Azhar University, Cairo, Egypt
}

\begin{abstract}
Problem statement: Many authors have studied k-out of-n repairable system with dependent failure and standby support. The question was raised whether the repair and standby units support increase the reliability of the system. Determine the efficiency of repair and standby support on the reliability of the system. Approach: In this study the statistical analysis of k-out of-n repairable system with dependent failure and standby support were discussed. Several reliability characteristics are obtained by using Kolmogorov's forward equations method. After the model is developed a particular case study is discussed to validate the theoretical results, a numerical computation are derived. Tables and graphs have been also given in the end. Results: The results indicated that the system with repair and standby support is better than the system without repair and standby support. Conclusion: These results indicated that the system with repair of its failed parts and standby redundancy facility increased the reliability of the system.
\end{abstract}

Key words: Cost analysis, Mean Time to System Failure (MTSF), steady-state availability, busy period, profit function, preventive maintenance, Kolmogorov's forward equations method

\section{INTRODUCTION}

When a system is constructed, it is assumed that the failure of any unit in k-out of-n systems does not affect the functioning of the system. Nevertheless, in practice, the failure of any working unit of a system results in the reduction of the efficiency of the whole system. It increases stress on the others ones and as the result, the failure rate of functional ones increased and the reliability of the system reduced. Thus, dependence occurs and as a result the failure rates of the units degrade.

The system with standby redundancy facility has been studied for many different system structures. In a redundant system, some additional parts are connected to the system. On the failure of the operating unit, a standby unit is switched on by perfect switching device. The redundancy in a system is usually employed to design highly reliable systems. Also the repairing failed component increases the reliability of the system. If resources are allocated to repair failed components, we should be able to keep for a much longer time.Thus introducing redundant parts and repairing a failed units may achieve high degree of reliability.

Many authors have discussed k-out of-n system with dependent failure rates ${ }^{[1,2]}$. The system reliability of modeling shared load was investigated by Shao and Lamberson et al. $^{[3]}$. Moustafa ${ }^{[4]}$ studied a transient analysis of reliability with and without repair for k-out of-n G systems. Pham ${ }^{[5]}$ studied availability and Mean Life Time of degraded system with partial repair. Who Kee Chang ${ }^{[6]}$, studied reliability analysis of a repairable parallel system with standby involving human and common-cause failure. Madhu Jain et al. ${ }^{[7]}$ studied kout of-n repairable system with dependent failure and standby support, but they didn't consider the cost analysis of the system.

The purpose of this study is to discuss cost analysis of k-out 0f-n: G system with active standby redundancy components and repair facility. The system is failed if $(\mathrm{k}+1)$ of its $\mathrm{n}$ components are failed. If resources are allocated to repair failed components, we should be able to keep the number of failed components below $\mathrm{n}+\mathrm{s}-\mathrm{k}+1$ for a much longer time. The failure and repair rate times follow exponential distribution. We analyze the system by using Kolmogorov's forward equations. Initially one unit is operative and the other is kept as cold standby. A particular case when no repair and standby support have been discussed. Tables and graphs have been also given in the end.

\section{System description:}

- The system consists of a main unit, n-subsystem and s-standbys

- The entire system is working if at least $k$ of its $n$ subsystems are operating 
- The system is failed when the number of working components goes down below $\mathrm{k}$

- All active components are follow exponential distribution

- The system is failed when the number of working components goes down below $\mathrm{k}$ or the number of failed components has reached $n+s-k+1$

- The failure and repair rate times follow exponential distribution

- The failure of main unit, which supervises the system, causes the total system failure and has a constant failure rate $\lambda_{\mathrm{p}}$

- The failure of fault coverage is constant and equal to $\lambda_{\mathrm{c}}$

- The failure rates of all subsystems are constant and same and depend on the number of working units and equal to $\lambda_{j},(j=1,2$.....n $)$

- When any of the operating subsystem fails, it is replaced by standby unit and failed unit goes to repair mode with rate $\mu_{\mathrm{i}}$. The standby units have constant failure rates $\beta$

- If all the standbys are consumed, the system works as degraded system until k-subsystems works

- When the system is down, no farther units can failed

- The state of the system is defined to be the number of failed components

The system state transition diagram is given in Fig. 1. State $i$ indicating that exactly $i$ subsystems are failed at time ' $\mathrm{t}$ ', $(\mathrm{i}=1,2, \ldots \ldots, \mathrm{n}+\mathrm{s}-\mathrm{k})$. The failure rate from state $\mathrm{i}$ to state $\mathrm{i}+1$ given by $\Delta_{\mathrm{i}}$. The state transition rate of the system is given by:

$\Delta_{\mathrm{i}}=\left\{\begin{array}{cc}\mathrm{n} \lambda_{\mathrm{n}}-(\mathrm{s}-\mathrm{i}) \beta & 0 \leq \mathrm{i} \leq \mathrm{s} \\ (\mathrm{n}+\mathrm{s}-\mathrm{i}) \lambda_{\mathrm{n}+\mathrm{s}-\mathrm{i}} & \mathrm{s}+1 \leq \mathrm{i} \leq \mathrm{n}+\mathrm{s}-\mathrm{k}\end{array}\right.$

The following system characteristics are obtained:

- Mean time to system failure (MTTF) with and without repair

- Steady state availability with and without repair

- Profit function

$\mathrm{Q}=\left[\begin{array}{cccccccc}-\left(\Delta_{0}+\lambda_{\mathrm{p}}+\lambda_{\mathrm{c}}\right) & \mu_{1} & 0 & 0 & \ldots & 0 & 0 & 0 \\ \Delta_{0} & -\left(\Delta_{1}+\lambda_{\mathrm{p}}+\mu_{\mathrm{i}}\right) & \mu_{2} & 0 & \ldots & 0 & 0 & 0 \\ 0 & \Delta_{1} & -\left(\Delta_{2}+\lambda_{\mathrm{p}}+\mu_{2}\right) & \mu_{3} & \ldots & 0 & 0 & 0 \\ \vdots & \vdots & \Delta_{2} & -\left(\Delta_{3}+\lambda_{\mathrm{p}}+\mu_{3}\right) & \ldots & \vdots & \vdots & 0 \\ \vdots & \vdots & \vdots & \vdots & \ddots & \vdots & \vdots & 0 \\ \vdots & \vdots & \vdots & \vdots & \ldots & \vdots & \vdots & 0 \\ \vdots & \vdots & \vdots & \vdots & \ldots & \vdots & \ldots & 0 \\ 0 & 0 & 0 & 0 & \ldots & \Delta_{\mathrm{n}+\mathrm{s}-\mathrm{k}-1}-\left(\Delta_{\mathrm{n}+\mathrm{s}-\mathrm{k}}+\lambda_{\mathrm{p}}+\mu_{\mathrm{n}+\mathrm{s}-\mathrm{k}}\right) & \mu_{\mathrm{n}+\mathrm{s}-\mathrm{k}+1} \\ 0 & 0 & 0 & 0 & \ldots & 0 & \Delta_{\mathrm{n}+\mathrm{s}-\mathrm{k}} & -\left(\mu_{\mathrm{n}+\mathrm{s}-\mathrm{k}+\mathrm{s}}\right)\end{array}\right]$

Formulation of mathematical model: If we let $\mathrm{P}(\mathrm{t})$ denote the probability row vector at time $t$, the initial conditions for this problem are:

$$
\mathrm{P}_{0}(0)=1, \mathrm{P}_{\mathrm{i}}(0)=0, \mathrm{i}=1,2, \ldots \ldots, \mathrm{n}+\mathrm{s}-\mathrm{k}+1
$$

By employing the method of linear first order differential equations For Fig. 1 and, we can obtain the following differential equations:

$$
\mathrm{P}_{0}^{\prime}(\mathrm{t})=-\left(\lambda_{0}+\lambda_{\mathrm{p}}+\lambda_{\mathrm{c}}\right) \mathrm{P}_{0}(\mathrm{t})+\mu_{1} \mathrm{P}_{1}(\mathrm{t})
$$

$$
\begin{gathered}
\mathrm{P}_{0}^{\prime}(\mathrm{t})=-\left(\Delta_{\mathrm{i}}+\lambda_{\mathrm{p}}+\mu_{\mathrm{i}}\right) \mathrm{P}_{\mathrm{i}}(\mathrm{t})+\Delta_{\mathrm{i}-1} \mathrm{P}_{\mathrm{i}-1}(\mathrm{t})+\mu_{\mathrm{i}+1} \mathrm{P}_{\mathrm{i}+1}(\mathrm{t}), \\
1 \leq \mathrm{i} \leq \mathrm{n}+\mathrm{s}-\mathrm{k}
\end{gathered}
$$

$P_{n+s-k+1}^{\prime}(t)=-\left(\mu_{n+s-k+1}\right) P_{n+s-k+1}(t)+\Delta_{n+s-k} P_{n+s-k}(t)$

Where:

$$
\begin{aligned}
& \Delta_{0}=4\left(\lambda_{4}\right)+2 \beta, \\
& \Delta_{1}=4\left(\lambda_{4}\right)+\beta, \\
& \Delta_{2}=4 \lambda_{4}, \\
& \Delta_{3}=3 \lambda_{3}
\end{aligned}
$$

This can be written in the matrix form:

$$
\mathrm{P}^{*}=\mathrm{QP}
$$

Where:

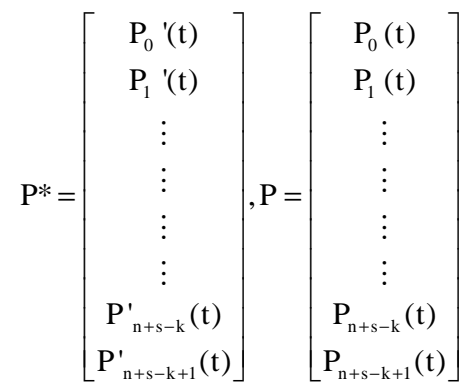




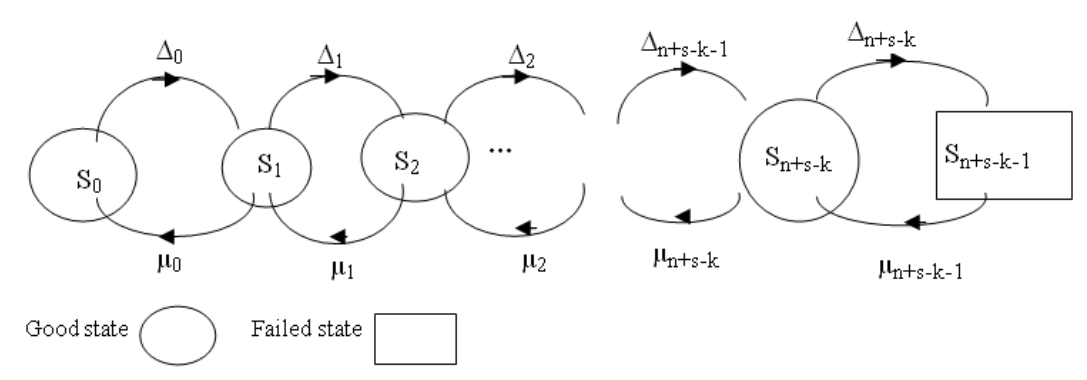

Fig. 1: State transition diagram

Particular case: If we put $\mathrm{n}=4, \mathrm{k}=3, \mathrm{~s}=2$, in equations (3-1)-(3-3), we obtain the matrix form:

$$
\mathrm{P}^{*}=\mathrm{QP}
$$

Where:

$$
\begin{aligned}
P^{*} & =\left[\begin{array}{l}
P_{0}{ }^{\prime}(t) \\
P_{1}{ }^{\prime}(t) \\
P_{2}{ }^{\prime}(t) \\
P_{3}{ }^{\prime}(t) \\
P_{4}{ }^{\prime}(t)
\end{array}\right] \\
P & =\left[\begin{array}{l}
P_{0}(t) \\
P_{1}(t) \\
P_{1}(t) \\
P_{1}(t) \\
P_{1}(t)
\end{array}\right]
\end{aligned}
$$$$
\mathrm{Q}=\left[\begin{array}{ccc}
0 & 0 & 0 \\
\mu_{2} & 0 & 0 \\
-\left(\Delta_{2}+\lambda_{\mathrm{p}}+\mu_{2}\right) & \mu_{3} & 0 \\
\Delta_{2} & -\left(\Delta_{3}+\lambda_{\mathrm{p}}+\mu_{3}\right) & \mu_{4} \\
0 & \Delta_{3} & -\mu_{4} \\
-\left(\Delta_{0}+\lambda_{\mathrm{p}}+\lambda_{\mathrm{c}}\right) & \mu_{1} \\
\Delta_{0} & -\left(\Delta_{1}+\lambda_{\mathrm{p}}+\mu_{\mathrm{i}}\right) \\
0 & \Delta_{1} \\
0 & 0 \\
0 & 0
\end{array}\right]
$$

Mean Time to System Failure (MTSF): Using the above-mentioned set of assumptions and method of linear first order differential equations, the mean time to system failure (MTSF) for the proposed system can be evaluated. To calculate the MTSF we take the transpose matrix of $\mathrm{Q}$ and delete the rows and columns for the absorbing state, the new matrix is called A. the expected time to reach an absorbing state is calculated from:

$$
\begin{aligned}
& \operatorname{MTSF}=\mathrm{P}(0)\left(-\mathrm{A}^{-1}\right)\left[\begin{array}{l}
1 \\
1 \\
1 \\
1
\end{array}\right] \\
& \mathrm{Q}=\left[\begin{array}{ccc}
-\left(\Delta_{0}+\lambda_{\mathrm{p}}+\lambda_{\mathrm{c}}\right) & \Delta_{0} & 0 \\
\mu_{1} & -\left(\Delta_{1}+\lambda_{\mathrm{p}}+\mu_{\mathrm{i}}\right) & \Delta_{1} \\
0 & \mu_{2} & -\left(\Delta_{2}+\lambda_{\mathrm{p}}+\mu_{2}\right) \\
0 & 0 & \mu_{3} \\
& 0 & \\
& 0 & \\
& \Delta_{2} & \\
& -\left(\Delta_{3}+\lambda_{\mathrm{p}}+\mu_{3}\right)
\end{array}\right.
\end{aligned}
$$

$$
\operatorname{MTTF}=\frac{\left(a_{1}+a_{2}+a_{3}\right)}{a_{4}}
$$

Where:

$$
\begin{aligned}
\mathrm{a}_{1}= & \left(\left(\Delta_{1}+\mu_{1}+\lambda_{\mathrm{p}}\right)\left(\left(\Delta_{2}+\mu_{2}+\lambda_{-}\{\mathrm{p}\}\right)\left(\Delta_{3}+\mu_{3}+\lambda_{\mathrm{p}}\right)-\Delta_{2} \mu_{3}\right)-\right. \\
& \left.\Delta_{1} \mu_{2}\left(\Delta_{3}+\mu_{3}+\lambda_{\mathrm{p}}\right)\right) \\
\mathrm{a}_{2}= & \Delta_{0}\left(\left(\Delta_{2}+\mu_{2}+\lambda_{\mathrm{p}}\right)\left(\Delta_{3}+\mu_{3}+\lambda_{\mathrm{p}}\right)-\Delta_{2} \mu_{3}\right) \\
\mathrm{a}_{3}= & \Delta_{0} \Delta_{1}\left(\left(\Delta_{3}+\mu_{3}+\lambda_{\mathrm{p}}\right)+\Delta_{2}\right) \\
\mathrm{a}_{4}= & \left(\Delta_{0}+\lambda_{\mathrm{p}}+\lambda_{\mathrm{c}}\right)\left(( \Delta _ { 1 } + \mu _ { 1 } + \lambda _ { \mathrm { p } } ) \left(\left(\Delta_{2}+\mu_{2}+\lambda_{\mathrm{p}}\right)\left(\Delta_{3}+\mu_{3}+\lambda_{\mathrm{p}}\right)-\right.\right. \\
& \left.\left.\Delta_{2} \mu_{3}\right)-\Delta_{1} \mu_{2}\left(\Delta_{3}+\mu_{3}+\lambda_{\mathrm{p}}\right)\right)-\Delta_{0} \mu_{1}\left(( \Delta _ { 2 } + \mu _ { 2 } + \lambda _ { \mathrm { p } } ) \left(\Delta_{3}+\mu_{3}+\right.\right. \\
& \left.\lambda_{\mathrm{p}}\right)-\Delta_{2} \mu_{3}
\end{aligned}
$$

When repair is not available, the Mean Time to System Failure (MTTF) is given by:

$\operatorname{MTTF}=\frac{\left(b_{1}+b_{2}+b_{3}\right)}{b_{4}}$ 
Where:

$\mathrm{b}_{1}=\left(\Delta_{1}+\lambda_{\mathrm{p}}\right)\left(\Delta_{2}+\lambda_{\mathrm{p}}\right)\left(\Delta_{3}+\lambda_{\mathrm{p}}\right)$

$\mathrm{b}_{2}=\left(\Delta_{2}+\lambda_{\mathrm{p}}\right)\left(\Delta_{3}+\lambda_{\mathrm{p}}\right) \Delta_{0}$

$\mathrm{b}_{3}=\Delta_{0} \Delta_{1}\left(\Delta_{2}+\Delta_{3}+\lambda_{\mathrm{p}}\right)$

$\mathrm{b}_{4}=\left(\Delta_{0}+\lambda_{\mathrm{p}}+\lambda_{\mathrm{c}}\right)\left(\Delta_{1}+\lambda_{\mathrm{p}}\right)\left(\Delta_{2}+\lambda_{\mathrm{p}}\right)\left(\Delta_{3}+\lambda_{\mathrm{p}}\right)$
Availability analysis: The initial conditions for this problem are the same as for the reliability case:

$$
P(0)=[1,0,0,0,0,]
$$

the differential equations form can be expressed as:

$$
\left[\begin{array}{l}
\mathrm{P}_{0}^{*} \\
\mathrm{P}_{1}^{*} \\
\mathrm{P}_{2}^{*} \\
\mathrm{P}_{3}^{*} \\
\mathrm{P}_{4}^{*}
\end{array}\right]=\left[\begin{array}{ccccc}
-\left(\Delta_{0}+\lambda_{\mathrm{p}}+\lambda_{\mathrm{c}}\right) & \mu_{1} & 0 & 0 & 0 \\
\Delta_{0} & -\left(\Delta_{1}+\lambda_{\mathrm{p}}+\mu_{\mathrm{i}}\right) & \mu_{2} & 0 & 0 \\
0 & \Delta_{1} & -\left(\Delta_{2}+\lambda_{\mathrm{p}}+\mu_{2}\right) & \mu_{3} & 0 \\
0 & 0 & \Delta_{2} & -\left(\Delta_{3}+\lambda_{\mathrm{p}}+\mu_{3}\right) & \mu_{4} \\
0 & 0 & 0 & \Delta_{3} & -\mu_{4}
\end{array}\right]\left[\begin{array}{l}
\mathrm{P}_{0} \\
\mathrm{P}_{1} \\
\mathrm{P}_{2} \\
\mathrm{P}_{3} \\
\mathrm{P}_{4}
\end{array}\right]
$$

In the steady state, the derivatives of the state probabilities become zero, i.e.:

$\mathrm{QP}(\infty)=0$

Then the steady state probabilities can be calculated as follows:

$\mathrm{A}(\infty)=\mathrm{P}_{0}(\infty)+\mathrm{P}_{1}(\infty)+\mathrm{P}_{2}(\infty)+\mathrm{P}_{4}(\infty)$

Then the matrix form became:

$$
\left[\begin{array}{ccccc}
-\left(\Delta_{0}+\lambda_{\mathrm{p}}+\lambda_{\mathrm{c}}\right) & \mu_{1} & 0 & 0 & 0 \\
\Delta_{0} & -\left(\Delta_{1}+\lambda_{\mathrm{p}}+\mu_{\mathrm{i}}\right) & \mu_{2} & 0 & 0 \\
0 & \Delta_{1} & -\left(\Delta_{2}+\lambda_{\mathrm{p}}+\mu_{2}\right) & \mu_{3} & 0 \\
0 & 0 & \Delta_{2} & -\left(\Delta_{3}+\lambda_{\mathrm{p}}+\mu_{3}\right) & \mu_{4} \\
0 & 0 & 0 & \Delta_{3} & -\mu_{4}
\end{array}\right]\left[\begin{array}{l}
\mathrm{P}_{0}^{*} \\
\mathrm{P}_{1}^{*} \\
\mathrm{P}_{2}^{*} \\
\mathrm{P}_{3}^{*} \\
\mathrm{P}_{4}^{*}
\end{array}\right]=\left[\begin{array}{l}
0 \\
0 \\
0 \\
0 \\
0
\end{array}\right]
$$

To obtain $\mathrm{P}_{0}(\infty)+\mathrm{P}_{1}(\infty)+\mathrm{P}_{2}(\infty)+\mathrm{P}_{4}(\infty)$ we solve the Eq. 3a by using following normalizing condition:

$\mathrm{P}_{0}(\infty)+\mathrm{P}_{1}(\infty)+\mathrm{P}_{2}(\infty)+\mathrm{P}_{3}(\infty)+\mathrm{P}_{4}(\infty)=1$

We substitute the Eq. 3c in any one of the redundant rows in equation to (3a) yield:

$$
\left[\begin{array}{ccccc}
-\left(\Delta_{0}+\lambda_{\mathrm{p}}+\lambda_{\mathrm{c}}\right) & \mu_{1} & 0 & 0 & 0 \\
\Delta_{0} & -\left(\Delta_{1}+\lambda_{\mathrm{p}}+\mu_{\mathrm{i}}\right) & \mu_{2} & 0 & 0 \\
0 & \Delta_{1} & -\left(\Delta_{2}+\lambda_{\mathrm{p}}+\mu_{2}\right) & \mu_{3} & 0 \\
0 & 0 & \Delta_{2} & -\left(\Delta_{3}+\lambda_{\mathrm{p}}+\mu_{3}\right) & \mu_{4} \\
1 & 1 & 1 & 1 & 1
\end{array}\right]\left[\begin{array}{l}
\mathrm{P}_{0}^{*} \\
\mathrm{P}_{1}^{*} \\
\mathrm{P}_{2}^{*} \\
\mathrm{P}_{3}^{*} \\
\mathrm{P}_{4}^{*}
\end{array}\right]=\left[\begin{array}{l}
0 \\
0 \\
0 \\
0 \\
0
\end{array}\right]
$$

The steady state availability $\mathrm{A}(\infty)$ is given by:

$$
A(\infty)=\frac{N}{D}
$$


Where:

$$
\begin{aligned}
\mathrm{N}= & \mathrm{B}_{0} \mathrm{~B}_{1} \mathrm{~B}_{2} \mu_{4}+\mu_{3} \mu_{4}\left(\mathrm{~B}_{0}\left(\mathrm{~B}_{1}+\mu_{2}\right)-\mu_{1}\left(\Delta_{0}+\mu_{2}\right)\right)- \\
& \mu_{4}\left(\Delta_{1} \mu_{2} \mathrm{~B}_{0}+\Delta_{0} \mu_{1} \mathrm{~B}_{2}\right) \\
\mathrm{D}= & \mathrm{B}_{0} \mathrm{~B}_{1}\left(\mathrm{~B}_{2}\left(\mathrm{~B}_{3}+\mu_{4}\right)-\Delta_{2} \mu_{3}+\mu_{3} \mu_{4}\right)+\mu_{4} \mu_{3} \mu_{2}\left(\mathrm{~B}_{0}+\mu_{1}\right)+ \\
& \mu_{3} \mu_{1} \Delta_{0}\left(\Delta_{2}-\mu_{4}\right)-\left(\mathrm{B}_{3}+\mu_{4}\right)\left(\Delta_{1} \mu_{2} \mathrm{~B}_{0}+\Delta_{0} \mu_{1} \mathrm{~B}_{2}\right)
\end{aligned}
$$

Where:

$\mathrm{B}_{0}=\left(\Delta_{0}+\lambda_{\mathrm{p}}+\lambda_{\mathrm{c}}\right)$

$\mathrm{B}_{1}=\left(\Delta_{1}+\lambda_{\mathrm{p}}+\mu_{1}\right)$

$\mathrm{B}_{2}=\left(\Delta_{2}+\lambda_{\mathrm{p}}+\mu_{2}\right)$

$\mathrm{B}_{3}=\left(\Delta_{3}+\lambda_{\mathrm{p}}+\mu_{3}\right)$

When there is no repair, the steady state availability of the system is given by:

$$
\mathrm{A}(\infty)=0
$$

Busy period analysis: The initial conditions for this problem are the same as for the reliability case: the differential equations form can be expressed as availability case.

Then the steady state busy period $\mathrm{B}(\infty)$ is given by:

$\mathrm{B}(\infty)=1-\mathrm{P}_{0}(\infty)=1-\frac{\mu_{1} \mu_{2} \mu_{3} \mu_{4}}{\mathrm{D}}$

When there is no repair, the steady state busy period of the system is given by:

$$
\mathrm{B}(\infty)=0
$$

Cost analysis: The expected total profit per unit time incurred to the system in the steady-state is given by:

$$
\begin{gathered}
\text { Profit }=\text { total revenue }- \text { total cost } \\
\mathrm{PF}=\mathrm{RA}(\infty)-\mathrm{CB}(\infty)
\end{gathered}
$$

When there is no repair, the steady state profit of the system is given by:

$$
\mathrm{PF}=0
$$

Where:

$\mathrm{PF}=$ The profit incurred to the system

$\mathrm{R}=$ The revenue per unit up-time of the system,

$\mathrm{C}_{1}=$ The cost per unit time which the system is under repair>

\section{MATERIALS AND METHODS}

Many authors have studied k-out of-n repairable system with dependent failure and standby support. The question was raised whether the repair and standby units support increase the reliability of the system. In this study the statistical analysis of k-out of-n repairable system with dependent failure and standby support were discussed to show the system with repair and standby support increase the reliability of the system.

We analyze the system by using Kolmogorov's forward equations method. After the model is developed a particular case study is discussed to validate the theoretical results. Next, some numerical computations are derived to show the effect of repair and standby support on the system.

\section{RESULTS}

If we put: $\lambda_{\mathrm{p}}=0.002, \lambda_{\mathrm{c}}=0.003, \lambda_{\beta}=0.005$, $\lambda_{4}=0.01, \lambda_{3}=0.03, \mu_{1}=0.1, \mu_{2}=0.2, \mu_{3}=0.3, \mu_{4}=$ 0.4 in Eq. $4 \mathrm{~b}$ and c; $5 \mathrm{~d}$ and e we get: $\Delta_{0}=0.05, \Delta_{1}=$ $0.045, \Delta_{2}=0.04, \Delta_{3}=0.09$ and obtain the Table 1-4:

- Table 1 show relation between failure rate $\lambda_{\mathrm{p}}$ and MTSF of the system (with repair and standby and with repair and without standby and without repair and standby)

- Table 2 show relation between failure rate $\lambda_{\mathrm{p}}$ and steady state availability of the system (with repair and standby and with repair and without standby)

- Table 3 show relation between failure rate $\lambda_{\mathrm{p}}$ and busy period of the system (with repair and standby and with repair and without standby)

Table 1: Relation between failure rate $\lambda_{\mathrm{p}}$ and the MTSF (with and without standby)

\begin{tabular}{llll}
\hline & $\begin{array}{l}\text { MTTF of the } \\
\text { system } \\
\text { with repair } \\
\text { and standby }\end{array}$ & $\begin{array}{l}\text { MTTF of the } \\
\text { system } \\
\text { with repair and } \\
\text { without standby }\end{array}$ & $\begin{array}{l}\text { MTTF of the } \\
\text { system } \\
\text { without repair } \\
\text { and standby }\end{array}$ \\
$\lambda_{\mathrm{p}}$ & 287.90 & 285.41 & 70.451 \\
0.001 & 223.53 & 221.98 & 67.259 \\
0.002 & 182.68 & 181.62 & 64.297 \\
0.003 & 154.45 & 153.68 & 61.545 \\
0.004 & 133.78 & 133.19 & 58.984 \\
0.005 & 117.99 & 117.52 & 56.595 \\
0.006 & 105.53 & 105.15 & 54.363 \\
0.007 & 95.456 & 95.132 & 52.276 \\
0.008 & 87.135 & 86.859 & 50.320 \\
0.009 & 80.148 & 79.910 & 48.485 \\
0.010 & & &
\end{tabular}

Table 2: Relation between failure rate $\lambda_{p}$ and steady state availability

\begin{tabular}{lll}
\hline$\lambda_{\mathrm{p}}$ & $\begin{array}{l}\text { Availability of the system } \\
\text { with repair and standby }\end{array}$ & $\begin{array}{l}\text { Availability of the system with } \\
\text { repair and without standby }\end{array}$ \\
\hline 0.001 & 0.98871 & 0.54005 \\
0.002 & 0.98552 & 0.53450 \\
0.003 & 0.98235 & 0.52907 \\
0.004 & 0.97921 & 0.52376 \\
0.005 & 0.97610 & 0.51856 \\
0.006 & 0.97302 & 0.51347 \\
0.007 & 0.96995 & 0.50848 \\
0.008 & 0.96692 & 0.50360 \\
0.009 & 0.96391 & 0.49881 \\
0.010 & 0.96092 & 0.49412 \\
\hline
\end{tabular}


Table 3: Relation between failure rate $\lambda_{\mathrm{p}}$ and the Busy Period of the

\begin{tabular}{lll} 
& system & \\
\hline$\lambda_{\mathrm{p}}$ & $\begin{array}{l}\text { Busy period of the system } \\
\text { with repair and without standby }\end{array}$ & $\begin{array}{l}\text { Busy period of the system } \\
\text { with repair and standby }\end{array}$ \\
\hline 0.001 & 0.42485 & 0.37431 \\
0.002 & 0.43562 & 0.38636 \\
0.003 & 0.44611 & 0.39810 \\
0.004 & 0.45635 & 0.40954 \\
0.005 & 0.46634 & 0.42070 \\
0.006 & 0.47609 & 0.43158 \\
0.007 & 0.48560 & 0.44218 \\
0.008 & 0.49488 & 0.45253 \\
0.009 & 0.50394 & 0.46261 \\
0.010 & 0.51279 & 0.47246
\end{tabular}

Table 4: Relation between failure rate $\lambda_{\mathrm{p}}$ and the profit (with and without standby)

\begin{tabular}{lll}
\hline$\lambda_{\mathrm{p}}$ & $\begin{array}{l}\text { The profit with } \\
\text { repair and standby }\end{array}$ & $\begin{array}{l}\text { The profit with repair } \\
\text { and without standby }\end{array}$ \\
\hline 0.001 & 946.23 & 502.62 \\
0.002 & 941.96 & 495.86 \\
0.003 & 937.74 & 489.26 \\
0.004 & 933.58 & 482.81 \\
0.005 & 929.47 & 476.49 \\
0.006 & 925.41 & 470.31 \\
0.007 & 921.39 & 464.26 \\
0.008 & 917.43 & 458.35 \\
0.009 & 913.52 & 452.55 \\
0.01 & 909.64 & 446.87 \\
\hline
\end{tabular}

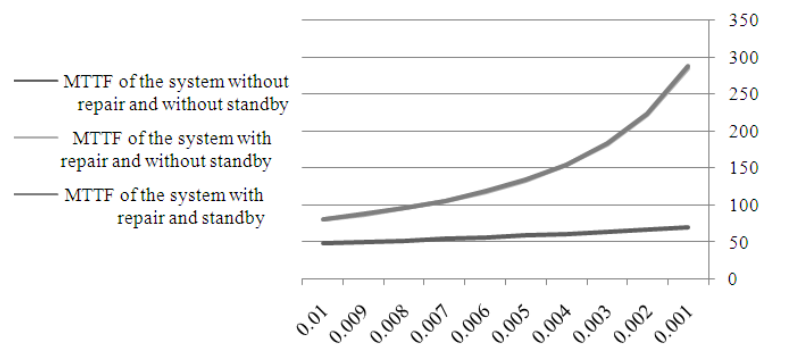

Fig. 2: Relation between the failure rate $\lambda_{\mathrm{p}}$ and the MTSF

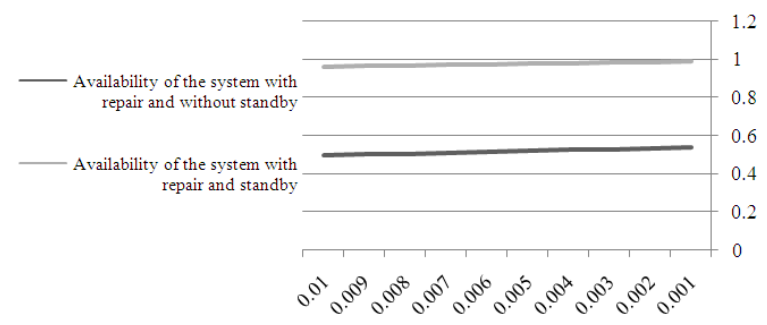

Fig. 3: Relation between the failure rate $\lambda_{\mathrm{p}}$ and the steady state availability

- Figure 3 show relation between the failure rate $\lambda_{\mathrm{p}}$ and steady state availability

- Figure 4 show relation between the failure rate $\lambda_{\mathrm{p}}$ and busy period

- Figure 5 show relation between the failure rate $\lambda_{\mathrm{p}}$ and expected total profit

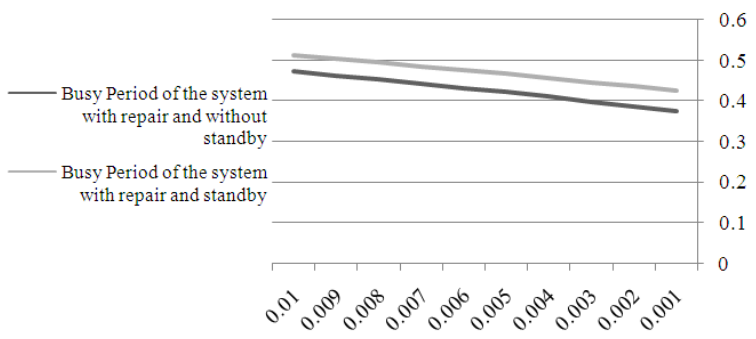

Fig. 4: Relation between the failure rate $\lambda_{\mathrm{p}}$ and the busy period

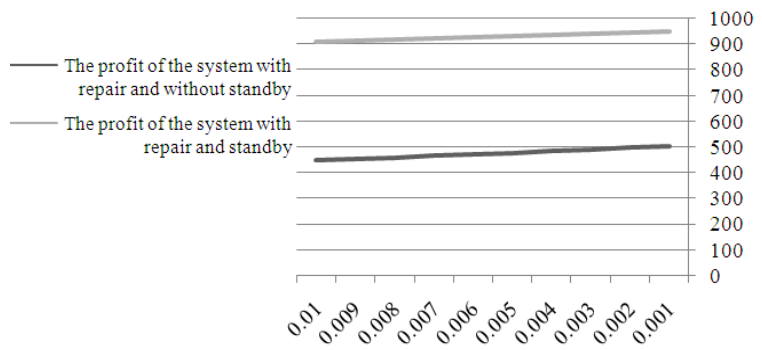

Fig. 5: Relation between the failure rate $\lambda_{\mathrm{p}}$ and the expected total profit

- Table 4 show relation between failure rate $\lambda_{\mathrm{p}}$ and expected total profit of the system (with repair and standby and with repair and without standby)

- Figure 2 show relation between the failure rate $\lambda_{p}$ and MTSF

\section{DISCUSSION}

By comparing the MTTF with respect to failure rate $\lambda_{p}$. theoretically and graphically. It was observing that: The increase of failure rate $\lambda_{\mathrm{p}}$ at constant $\lambda_{\mathrm{c}}=0.003, \lambda_{\beta}=0.007, \lambda_{4}=0.01, \lambda_{3}=0.03$, $\mu_{1}=0.1, \mu_{2}=0.2, \mu_{3}=0.3, \mu_{4}=0.4, \mathrm{R}=1000, \mathrm{C}=100$, the MTTF of the system decreases for both systems with repair and standby and with repair and without standby and without repair and standby. We conclude that: the MTTF of the system with repair and standby is longer than the system without repair and standby, i.e., the system with repair and standby is better than the system without repair and standby.

By comparing the busy period with respect to failure rate $\lambda_{p}$ theoretically and graphically. It was observing that: The increase of failure rate $\lambda_{\mathrm{p}}$ at constant $\lambda_{\mathrm{c}}=0.003, \lambda_{\beta}=0.007, \lambda_{4}=0.01, \lambda_{3}=0.03$, $\mu_{1}=0.1, \mu_{2}=0.2, \mu_{3}=0.3, \mu_{4}=0.4, \mathrm{R}=1000, \mathrm{C}=100$, busy period increases for both systems with repair and standby and with repair and without standby. We 
conclude that: the busy period of the system with repair and standby is greater than the system with repair and without standby.

Also, by comparing the steady state availability and the profit with respect to failure rate $\lambda_{p}$ theoretically and graphically. It was observing that: The increase of failure rate $\left(\lambda_{\mathrm{p}}\right)$, at constant, $\lambda_{\mathrm{c}}=0.003$, $\lambda_{\beta}=0.007, \lambda_{4}=0.01, \lambda_{3}=0.03, \mu_{1}=0.1, \quad \mu_{2}=0.2$, $\mu_{3}=0.3, \mu_{4}=0.4, \mathrm{R}=1000, \mathrm{C}=100$, the steady state availability and the profit function of the system decreases for both systems with repair and standby and with repair and without standby.

\section{CONCLUSION}

We conclude also that: the steady state availability and the profit of the system with repair and standby is greater than the system with repair and without standby. i.e., the system with repair and standby is better than the system with repair and without standby.

\section{REFRENCES}

1. Moustafa, S.M., 1997. Reliability analysis of k-out of-n systems with dependent failures and imperfect coverage. Reliab. Eng. Syst. Safe., 58: 15-17. DOI: 10.1016/S0951-8320(97)00050-1

2- Pham, H., 1997. Reliability analysis of a high voltage system with dependent failure and imperfect coverage. Reliab. Eng. Syst. Safe., 37: $25-28$

3. Shao, J. and L.R. Lamberson, 1991. Modeling a shared-load k-out of-n: G systems. IEEE Trans. Reliab., 40: 205-209. DOI: 10.1109/24.87129
4. Mostafa, S.M., 1998. Transient analysis of reliability with and without repair for k-out of-n: G systems with $\mathrm{M}$ failure modes. Reliab. Eng. Syst. Safe., 59: 317-320.

5. Pham, H., A. Suprasad and R.B. Misra, 1997. Availability and mean life time predication of multistage degraded system with partial repair. Reliab. Eng. Syst. Safe., 56: 169-173. DOI: 10.1016/S0951-8320(96)00140-8

6. Who Kee Chang, 1987. Reliability analysis of a repairable parallel system with standby involving human failure and common-cause failures, Microelectron. Reliability, 27: 269-271.

7. Madhu Jain, G., C. Sharma and Alok Kumar, 2002. K-out of-n repairable system with dependent failure and standby support. JKAU. Eng. Sci., 14: 73-83. 